\title{
On the Persistence of Energy Poverty in Europe: How Hard Is It for the Poor to Escape?
}

\author{
Lilia Karpinska, Sławomir Śmiech² (D) \\ 1 Department of Statistics, Cracow University of Economics, Cracow, Poland, 2 Department of Statistics, Cracow University of Economics, Cracow, \\ Poland \\ Keywords: energy poverty, persistence, europe \\ https://doi.org/10.46557/001c.14158
}

\section{Energy RESEARCH LETTERS}

Vol. 1, Issue 3, 2020

\begin{abstract}
The study offers first evidence on the persistence of energy poverty (EP) in 26 European countries. We examine the interaction between EP and subjective poverty in the long run. We apply the Markov process and clustering techniques to micro-level longitudinal data from the EU Survey on Income and Living Conditions. The results show that, on average, poverty makes it about two times harder to escape EP. We identify three groups of countries having similar transition probability paths.
\end{abstract}

\section{Introduction}

An adequate level of essential energy services is crucial for living a dignified life (Energy Poverty Observatory, 2020). The shortage of energy services is defined as energy poverty (EP). It is commonly accepted that EP is distinct from income poverty, but the link between the two conditions is complex. In comparative micro-level studies, inter alia, income poverty is considered an important factor of EP analysis (Karpinska \& Śmiech, 2020; Thomson \& Snell, 2013). For example, poor housing triggers health effects, which are consequences of both poverty and EP. In this study, we answer two research questions previously unaddressed:

1. How persistent is EP across European countries ${ }^{1}$ and what are the chances of the poor escaping EP?

2. How similar are European countries in terms of EP, poverty and severe poverty (SP) persistence?

These research questions are important because EP dynamics are an understudied subject for European countries. Most of the comparative studies focus on estimating the rate of EP and end up ignoring the underlying dynamics of the issue. Moreover, analysis of EP persistence is dominated by single-country approaches and is limited to a few countries, such as France, the UK, and Spain (Chaton \& Lacroix, 2018; Phimister et al., 2015; Roberts et al., 2015).

Our approach to the analysis is as follows. We choose subjective measures of EP and poverty, i.e. the ability to keep home warm and the ability to make ends meet respectively, to examine EP persistence in 26 European countries. Our examination is based on the recent four waves (2015-2018) of longitudinal microdata from the EU Survey on Income and Living Conditions (SILC). Subjective EP indicator is recommended by the EU Commission (Energy Poverty Observatory, 2020) and is frequently used in microlevel cross-country comparisons (Dubois \& Meier, 2016; Thomson \& Snell, 2013). The subjective poverty measure captures perceptions of living standards in each country
(Buttler, 2013), overcoming the limitations of income-based measures and providing a broader picture of poverty. The main assumption is related to discrete state space discretetime Markov chains (DTMC), i.e. time- and statistical units' homogeneousness.

We find that EP is a less stable state than poverty, and poverty makes it about two times harder to escape EP. We contribute to the literature on EP persistence by being the first to (a) conduct a comparative analysis on EP persistence in Europe, and (b) examine the dynamic interactions between EP and poverty.

The rest of the study is organized as follows. In the next section, we present data and methodology. In section 3, results are discussed. The last section concludes with policy implications.

\section{Data and methodology}

The study draws on the EU-SILC micro-level longitudinal data compiled by Eurostat yearly. The dataset is administered across the vast majority of the EU countries as well as some non-EU countries and is primarily focused on poverty issues. The study is conducted for 26 European countries; see country list in Footnote 1. We use household data from the latest EU-SILC release spanning the years 2015 to 2018. Household panels are made balanced. Sample size varies from 2,596 (Ireland) to 21,456 (Greece) households.

The ability to keep home warm (HH050) is used to measure EP and the ability to make ends meet (HS120) is used to measure poverty. Respondents can answer 'yes' or 'no' to the first question: "can your household afford to keep its home adequately warm?”. Respondents choose scores on a scale of 1 - 'with great difficulty' to 6 - 'very easily' to the second question: "thinking of your household's total income, is your household able to make ends meet (that is, to pay for its usual necessary expenses?"). In addition, households responding 1 or 2 to the second question are classified as poor.

The descriptive statistics are presented in Table 1. In the 
Table 1. Summary statistics - the share of energy poor and poor households in total number of households

\begin{tabular}{|c|c|c|c|c|c|c|c|c|}
\hline \multirow[t]{2}{*}{ Variable/year } & \multicolumn{2}{|c|}{ Median } & \multicolumn{2}{|c|}{ Minimum } & \multicolumn{2}{|c|}{ Maximum } & \multicolumn{2}{|l|}{ SD } \\
\hline & 2015 & 2018 & 2015 & 2018 & 2015 & 2018 & 2015 & 2018 \\
\hline Energy poverty & 6.33 & 4.96 & 0.12 & 0.37 & 41.22 & 40.3 & 10.64 & 9.94 \\
\hline Poverty & 24.29 & 19.77 & 2.49 & 1.99 & 71.55 & 73.55 & 19.45 & 18.69 \\
\hline
\end{tabular}

This table provides statistics for variables HH050 (ability to keep home warm) - a measure of energy poverty - and HS120 (ability to make ends meet ) - a measure of poverty. The median, minimum, and maximum values are presented in percentage. SD is a standard deviation. Data are obtained from the EU-SILC panel data, waves 2015-2018. The total sample size is 46,346 households.

observed period (2015-2018), the scale of EP in Europe is significantly lower than the scale of poverty. The greatest difference is noted concerning minimum values: poverty is 20 times higher than EP. Statistics show a significant amount of variation in EP and poverty rates.

Following the research questions defined in the introduction, we conduct the analysis in two steps. First, we use a Markov process to assess EP and poverty mobility as well as the presence of any absorbing states, i.e. the state, where the retention rate is $100 \%$. Second, we perform hierarchical clustering (HC) to identify countries with similar transition patterns and address the problem of EP and poverty persistence from a policy-making perspective.

Markov chain models, including their mover-stayer extension, are widely applied in studying social dynamics (Cappellari \& Jenkins, 2004). We propose a first-order DTMC to build a multi-state stochastic model, where households move across four states $S=\left\{S_{1}=\right.$ severely poor, $\mathrm{S}_{2}=$ energy poor, $\mathrm{S}_{3}=$ poor, $\mathrm{S}_{4}=$ non-poor $\}$. $\mathrm{S}_{1}$ corresponds to the presence of EP and poverty, $S_{4}$ signifies an absence of EP and poverty, and the rest is either EP or poverty. In the DTMC process $\left\{X_{n}\right\}$, the probability of transitions in and out of initial states $(i, j)$ is independent of time $(n \geq 0)$ and is described as follows:

$$
P\left(X_{1}=j \mid X_{0}=i\right)=P_{i j}
$$

We consider the one-step transition probability matrix with rows summing to one:

$$
P=\left[\begin{array}{llll}
p_{11} & p_{12} & p_{13} & p_{14} \\
p_{21} & p_{22} & p_{23} & p_{24} \\
p_{31} & p_{32} & p_{33} & p_{34} \\
p_{41} & p_{42} & p_{43} & p_{44}
\end{array}\right]
$$

After obtaining the respective matrices for 26 countries, we explore the geographical distribution of mobility paths by performing HC. Based on Ward's method of minimizing within-cluster variance, we identify groups of countries with similar transition probabilities. The HC function allows assessing the relationship between objects on a bottom-up basis. Accounting for clustering results, we further analyze retention rates in three deprivation states, such as $\mathrm{EP}$, poverty, and SP in Europe.

The analysis is performed in the $\mathrm{R}$ statistical software using the Markov chain package developed by Spedicato \& Signorelli (2014) and the HC algorithm available in the cluster library.

\section{Results and discussion}

In the first step of the analysis, we compute transition matrices by applying DTMC. In one-step transition proba-

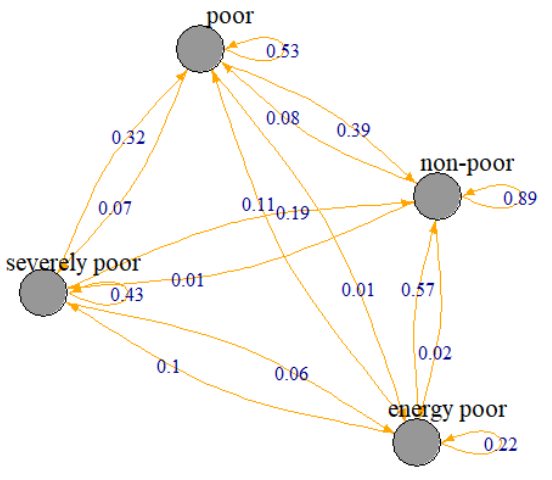

Figure 1: One-step transition probability plot based on mean values, Europe

This figure shows the transition probability diagram on a scale of zero to one, calculated based on the DTMC procedure. The average values of individual transition probability matrices for 26 countries are reported.

bility analysis, we identify no absorbing states in either of the 26 countries. It follows that neither EP nor poverty constitute a trap. Maximum and minimum escape rates are reported for Norway and Bulgaria, respectively. The chances of escaping EP by moving to a non-poverty state are from $100 \%$ to $7.1 \%$. Compared to EP, the probability of making a transition from poverty to non-poverty states is lower and varies from $4.5 \%$ to $63.3 \%$. SP has the lowest escape rate, in the $5.9 \%$ and $50 \%$ range.

On average, the estimated retention rate in Europe is $53 \%$ for poverty, $43 \%$ for SP, and $22 \%$ for EP (Figure 1 ). Poverty exhibits the greatest persistence. The average estimates for Europe show that it is roughly two times harder for the poor to escape EP. An important implication in this regard is that poverty is the major obstacle to recovery from EP. A transition from EP to non-poverty is the most intense (at $57 \%$ ), meaning that EP is not a stable state and more than half of all households have a chance of escaping EP over the four years of data we have.

In the second step of the analysis, we conduct HC to examine the most common transition probability patterns in Europe and identify similar groups of countries. Three distinct groups are identified from the HC algorithm (Figure 2).

The first group (Austria, Switzerland, Estonia, Finland, Norway, and Sweden) is characterized by low retention rates in all states. On average, the chances of staying in the nonpoverty state in this group is $95.5 \%$. Mobility within EP, poverty and SP is limited compared to other groups. The on- 


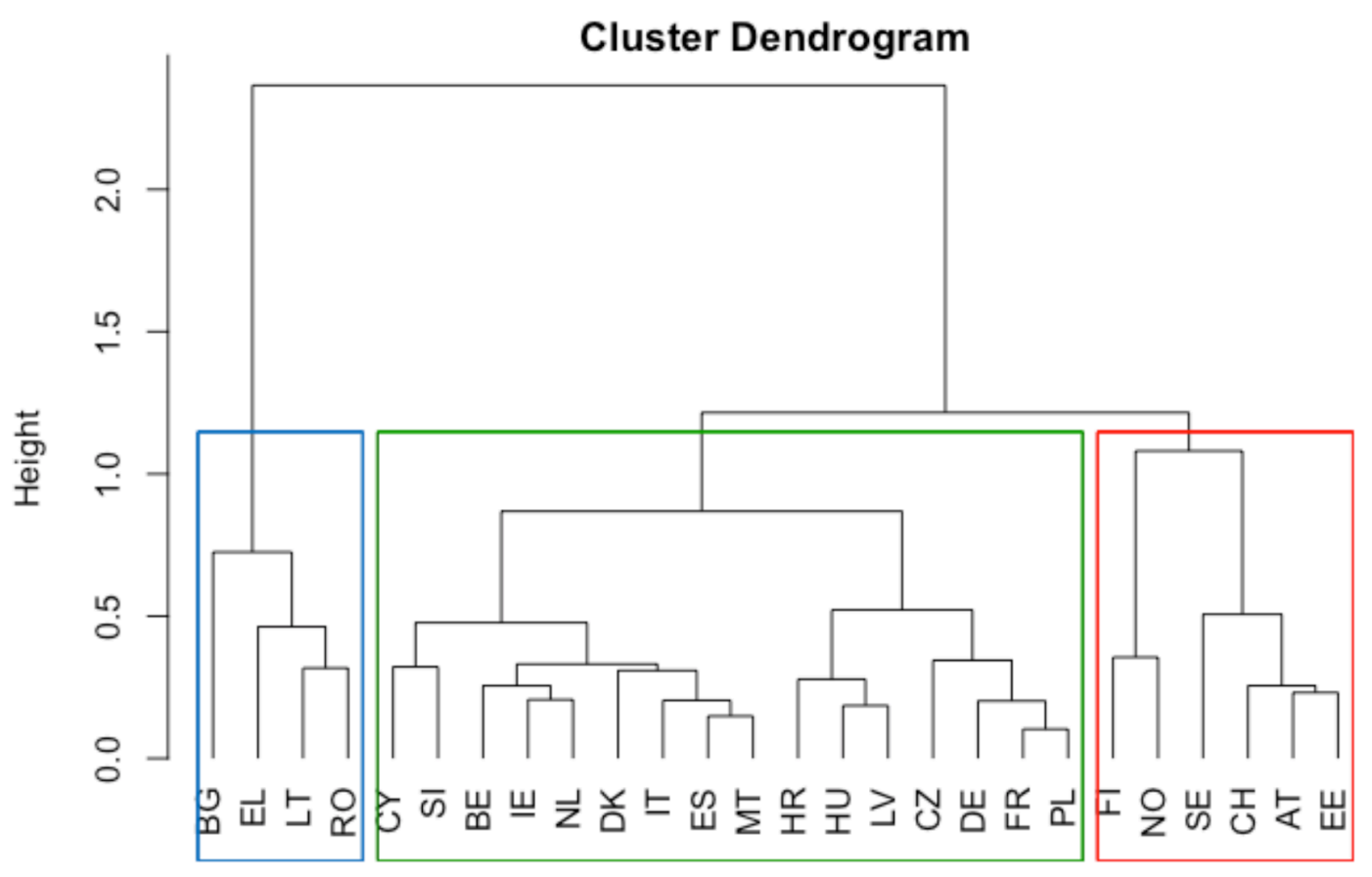

Figure 2: Hierarchical clustering based on transition matrices

This figure plots hierarchical clustering results calculated based on transition probability matrices for 26 countries. The Ward's criterion is applied.

ly exception is the transition from SP to poverty that fluctuates widely between zero and $66.7 \%$. Group one seems to be less affected by the vicious cycle of deprivation. In this group, the chances of the poor remaining in EP are almost three times higher than the chances of non-poor families.

The second group has the most number of countries (Belgium, Cyprus, Czechia, Denmark, Germany, Spain, France, Croatia, Hungary, Ireland, Italy, Latvia, Malta, the Netherlands, Poland, and Slovenia). Transition rates for this group reflect the average European results. Poor households in this group have twice as high a probability of staying in EP as other families. There are outliers at the upper boundary when it comes to migrating from SP to EP, namely Denmark (20\%) and Germany (17\%). The overall tendency, however, is that from SP families transit to poverty (33.6\%) or stay in SP (40.5\%). What distinguishes this group is a relatively high transition from EP to poverty (14.4\%).

By contrast, in group three (Bulgaria, Greece, Lithuania, and Romania) EP, poverty and SP are more persistent. This observation is consistent with studies pointing at some Southern and Eastern European countries being more affected by EP (Bouzarovski \& Tirado-Herrero, 2017). Looking at the distribution of retention rates, the minimum retention rate here is much higher than the maximum values in other groups. The average transition from EP is made mostly in the non-poverty (at 18.1\%) and SP (at 13.5\%) directions. The retention rate of EP (61.4\%) is lower than that of SP (75.9\%), indicating some role of poverty in escaping EP. In this group, a high average poverty persistence (77.8\%) and the poverty scale $(51.6 \%)$ should be accounted for in discussing the probability of the poor escaping EP.

Figure 3 presents the three-dimensional distribution of persistence rates across Europe. Countries from the third group struggle with EP, poverty and SP the most. A difficult situation is in Bulgaria that experiences high EP (86\%), SP (96.1\%) and poverty (93\%) persistence. The plot illustrates the lack of cohesion especially among countries of the third group and the rest of Europe, which is a good indicator of policy drawbacks. Although neither of the predicaments constitutes a trap, extremely high retention rates suggest difficult movement out of EP, SP or poverty.

\section{Conclusions and policy implications}

Based on the one-step transition probability matrices, we find three distinct groups of countries. The first group i.e. Austria, Switzerland, Estonia, Finland, Norway, and Sweden has high mobility between states and low EP, poverty and SP persistence. The second group (Belgium, Croatia, Cyprus, Czechia, Dania, France, Germany, Hungary, Ireland, Italy, Latvia, Malta, the Netherlands, Norway, Poland, Slovenia, and Spain) demonstrates close to average European results. Our average estimates for Europe show that the most persistent is poverty (at $53 \%$ ), SP is a slightly less stable state (at $43 \%$ ), whereas EP itself is the easiest situation to exit. In Europe, poverty makes it roughly twice as hard to escape EP. The third group (Bulgaria, Greece, Lithuania and Romania) faces great challenges due to exceptionally high retention rates in all states. Even though we do not identify absorbing states, the situation is close to a trap.

We consider two levels of policy implications. Firstly, uneven distribution of EP, SP and poverty persistence among countries points to a lack of regional cohesion within Europe. The striking difference between the third cluster and the rest of Europe calls for strengthening specifically tailored social policies and fostering territorial connectivity of the EU with the countries from the third group, where mobility across states is very low. Secondly, since EP is more persistent in a group of poor households, close attention of national policy-makers should be drawn to a severely poor group of population. Poverty reduction tools effective in individual countries can effectively contribute to EP alleviation. 
- group $1 \bullet \operatorname{group} 2 \bullet \operatorname{group} 3$

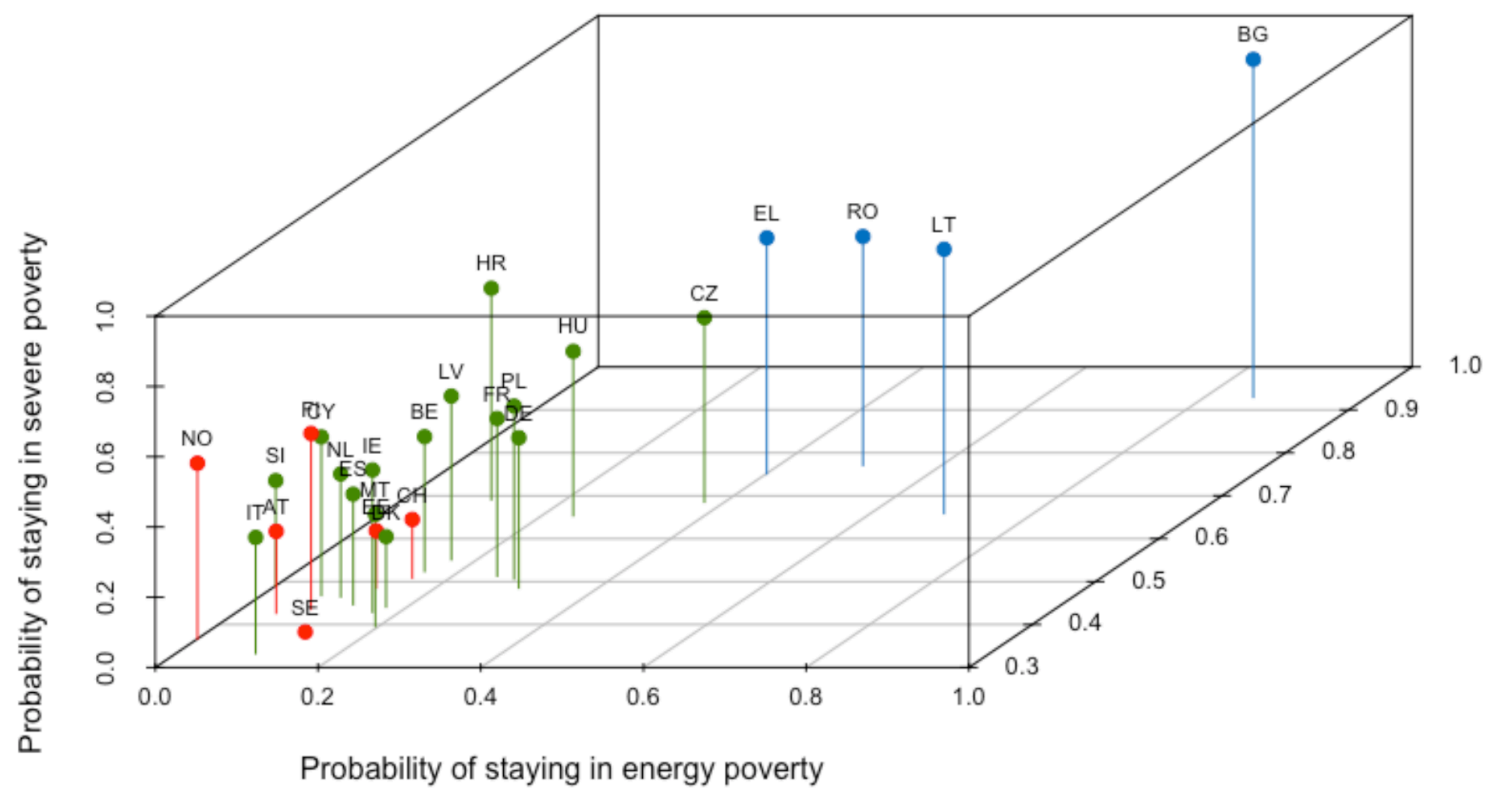

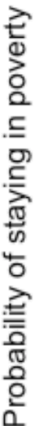

Figure 3: Three-dimensional plot of energy poverty, poverty, severe poverty persistence in Europe

This figure plots the energy poverty, poverty and severe poverty persistence rates for 26 countries obtained from the DTMC process on a scale of zero to one.

\section{Acknowledgement}

The access to the EU-SILC micro-data is granted by Eurostat within the framework of the Research Project Proposal 204/2018-EU-SILC. The authors gratefully acknowledge fi- nancial support from the National Science Centre in Poland (grant no 2018/29/N/HS4/02813).

The authors would like to thank the editor and reviewers of this journal for their valuable feedback.

This is an open-access article distributed under the terms of the Creative Commons Attribution 4.0 International License (CCBY-SA-4.0). View this license's legal deed at https://creativecommons.org/licenses/by-sa/4.0 and legal code at https://creativecommons.org/licenses/by-sa/4.0/legalcode for more information. 


\section{REFERENCES}

Bouzarovski, S., \& Tirado-Herrero, S. (2017). The energy divide: Integrating energy transitions, regional inequalities and poverty trends in the European Union. European Urban and Regional Studies, 24(1), 69-86. https://doi.org/10.1177/096977 $\underline{6415596449}$

Buttler, F. (2013). What determines subjective poverty? An evaluation of the link between relative income poverty measures and subjective economic stress within the EU. DFG Research Unit Horizontal Europeanization, Oldenburg.

Cappellari, L., \& Jenkins, S. P. (2004). Modelling Low Income Transitions. Journal of Applied Econometrics, 19(5), 593-610. https://doi.org/10.1002/jae.778

Chaton, C., \& Lacroix, E. (2018). Does France have a fuel poverty trap? Energy Policy, 113, 258-268. http s://doi.org/10.1016/i.enpol.2017.10.052

Dubois, U., \& Meier, H. (2016). Energy affordability and energy inequality in Europe: Implications for policymaking. Energy Research \& Social Science, 18, 21-35. https://doi.org/10.1016/j.erss.2016.04.015
Energy Poverty Observatory. (2020). https://www.ener gypoverty.eu/indicators-data

Karpinska, L., \& Śmiech, S. (2020). Invisible energy poverty? Analysing housing costs in Central and Eastern Europe. Energy Research and Social Science, 101670.

Phimister, E., Vera-Toscano, E., \& Roberts, D. (2015). The Dynamics of Energy Poverty: Evidence from Spain. Economics of Energy \& Environmental Policy, 4(1). https://doi.org/10.5547/2160-5890.4.1.ephi

Roberts, D., Vera-Toscano, E., \& Phimister, E. (2015). Fuel poverty in the UK: Is there a difference between rural and urban areas? Energy Policy, 87, 216-223. htt ps://doi.org/10.1016/j.enpol.2015.08.034

Spedicato, G. A., \& Signorelli, M. (2014). The markovchain Package: A Package for Easily Handling Discrete Markov Chains in $R$.

Thomson, H., \& Snell, C. (2013). Quantifying the prevalence of fuel poverty across the European Union. Energy Policy, 52, 563-572. https://doi.org/10.1016/ j.enpol.2012.10.009 